\title{
Information Gatekeepers and Price Discrimination on the Internet
}

\author{
Michael R. Baye \\ Indiana University \\ Email: mbaye@indiana.edu \\ Phone: (812) 855-2779 \\ Fax: (812) 855-3354
}

\author{
John Morgan \\ Princeton University \\ Email: rjmorgan@princeton.edu \\ Phone: (609) 258-4842 \\ Fax: (609) 258-2809
}

Economics Letters, forthcoming.

\begin{abstract}
When identical firms pay a fee to list prices at a price comparison site and can price discriminate between consumers who do and don't use the site, prices listed at the site are dispersed but lower than at firms' own websites. (JEL Numbers: D4, D8, M3, L13. Keywords: Internet, Price Dispersion, Price Discrimination)
\end{abstract}

\section{Introduction}

In a recent paper, Baye and Morgan (2001) provide an equilibrium model of pricing on the Internet that is relevant when firms and consumers can transmit and acquire price information through a monopoly gatekeeper. ${ }^{1}$ In their model, the information gatekeeper is best viewed as a price comparison site such as Shopper.com. Their model assumes that firms cannot price discriminate between consumers who use the price comparison site and those who do not. While this assumption is reasonable in many settings, ${ }^{2}$ in view of the relative technological ease with which firms that compete on the Internet could price discriminate, an important question is whether the price dispersion predicted by Baye-Morgan (2001) depends on their assumption

\footnotetext{
${ }^{1}$ For other models of E-Commerce, see Stahl (2000) and Caillaud and Jullien (2001).

${ }^{2}$ For instance, Baye, Morgan, and Scholten (2001) examined 4 million price quotes for 1000 of the best-selling electronics products listed at Shopper.com. While they found considerable price dispersion for identical electronics products, an audit of prices posted by firms at Shopper.com and at individual firm websites revealed little evidence of price discrimination during the 2000-2001 time period.
} 
that firms cannot price discriminate. This question is not purely academic, as is evidenced by the recent controversy surrounding Amazon.com's attempts to price discriminate.

We show that when firms pay a positive fee to list a price at the price comparison site, but can price discriminate between consumers shopping through the site and those who do not, prices remain dispersed at the gatekeeper's site. However, price dispersion is not present at individual firms' sites, as each firm posts the monopoly price at its own website. This implies that, when firms can price discriminate, the price a firm lists at a price comparison site is lower than the price it posts at its own website with probability one.

\section{Model and Results}

There are $n$ identical risk-neutral firms that sell a homogeneous product at a constant marginal cost of $c$. For a fee of $\phi>0$, firm $i$ can post a price $p_{i} \in[0, r]$ at a price comparison site. Consumers who access this price comparison site can "click through" to the firm and secure the product at that price. In contrast to Baye and Morgan (2001), we permit price discrimination: firm $i$ may charge a different price to consumers who purchase the item directly from the firm's website rather than by using the price comparison site.

There is a continuum of consumers (which we normalize to have unit mass). For simplicity, we assume that each consumer has unit demand up to the monopoly price of $r,(0<r<\infty)$. A fraction $\mu \in(0,1]$ of these consumers have access to the price comparison site and a fraction $(1-\mu)$ do not. Consumers can shop by using the price comparison site, by sequentially searching the websites of competing firms at a cost of $\varepsilon$ per search, or both. We assume that the consumer surplus at the monopoly price $(r)$ is sufficient to justify the cost of the initial search $(\varepsilon)$.

Firms simultaneously make pricing decisions, and then consumers shop and (possibly) purchase the product. In contrast to Baye-Morgan (2001), we treat $\phi$ and $\mu$ as exogenous parameters. Since the analysis that follows holds for a range of $\phi$ and $\mu$ 's, the results below can readily be used to endogenize fee-setting $(\phi)$ and subscription $(\mu)$ decisions; see Nahm (2001) for interesting heuristic insights on this issue.

We now establish that, when $\frac{n}{n-1} \frac{\phi}{\mu}+c<r$, there exists a symmetric equilibrium wherein the prices posted at the price comparison site are dispersed. Furthermore, the price each firm lists at the price comparison site is lower (with probability one) than the price charged to consumers who purchase directly from a firm's website.

To see this, consider the following putative equilibrium pricing and shopping strategies: Each firm posts a price at the gatekeeper's site with probability $\gamma \in(0,1)$, where the price posted is drawn from an atomless distribution $G$ with support $\left[p_{L}, r\right]$. In addition, each firm posts a price of $r$ on its own site. Consumers who have access to the price comparison site view the (possibly degenerate) list of prices offered at 
the site and click through to purchase from the firm offering the lowest price, provided that price does not exceed $r$. If no prices at or below $r$ are listed at the price comparison site, or if a consumer does not have access to the site, she simply chooses a firm at random and purchases if its price does not exceed $r$.

To establish that these pricing and shopping strategies comprise a Nash equilibrium, we first establish that the putative consumer shopping strategies are optimal given the posited firm pricing strategies. First, consider a consumer who does not have access to the price comparison site. Since the consumer rationally anticipates that all firms post a price of $r$ on their own websites, she can do no better than to economize on search costs by choosing a firm at random and purchasing if the price posted on its website does not exceed $r$.

Next, consider a consumer who does have access to the price listing service. Since any price listed at the gatekeeper's site is less than or equal to $r$, and since firms are believed to be charging $r$ at their own websites, such a consumer can do no better than to buy from the firm listing the lowest price on the gatekeeper's site if such a listing exists. Failing this, such a consumer can do no better than to engage in a shopping strategy identical to a consumer without access to the price comparison site.

Thus, we have established the optimality of consumer shopping behavior given the posited behavior of firms. We now establish the optimality of firm pricing decisions given the posited shopping behavior of consumers.

First, we show that it is optimal for a firm to charge the monopoly price at its own website. To see this, suppose a firm deviates by posting a price $p^{\prime} \neq r$ on its own website. Clearly, a firm cannot gain by pricing above the monopoly price, so suppose $p^{\prime}<r$. Given that consumer shopping behavior is as described above, pricing below $r$ generates no more sales on its website than when it charges the monopoly price. Hence, this is not a profitable deviation. We conclude that a firm can do no better than to post a price $r$ at its own website.

Next, consider a firm's decision regarding the posting of a price at the comparison site. A firm lists its price at the gatekeeper's site with probability $\gamma$, and the price posted there is drawn from the atomless distribution $G$ with support $\left[p_{L}, r\right]$. (Notice that $(\gamma, G)$ plays the role of $(\alpha, F)$ in Baye and Morgan (2001).) Each firm lists a price of $r$ at its own site. Given the search behavior of consumers and the posited pricing strategy of rival firms, the expected profits of a firm posting a price $p \in\left[p_{L}, r\right]$ on the price comparison site are:

$$
\begin{aligned}
E \pi_{i}(A, p) & =\frac{1-\mu}{n}(r-c)+\left(\sum_{j=0}^{n-1} \gamma^{j}(1-\gamma)^{n-1-j}\left(\begin{array}{c}
n-1 \\
j
\end{array}\right)(1-G(p))^{j}\right) \mu(p-c)-\phi \\
& =\frac{1-\mu}{n}(r-c)+(1-\gamma G(p))^{n-1} \mu(p-c)-\phi,
\end{aligned}
$$

where the second equality follows from the Binomial Theorem. 
In equilibrium, this expression must be constant for all prices in the support of G. Thus,

$$
\frac{1-\mu}{n}(r-c)+(1-\gamma G(p))^{n-1} \mu(p-c)-\phi=k .
$$

A firm that does not list a price on the gatekeeper's site earns expected profits of:

$$
E \pi_{i}(N A)=\frac{1-\mu}{n}(r-c)+\frac{\mu}{n}(r-c)(1-\gamma)^{n-1} .
$$

For a firm to be indifferent between listing a price on the gatekeeper's site and not listing, i.e. for $\gamma \in(0,1)$, it must earn the same expected profits under either scenario. Hence, for any $p \in\left[p_{L}, r\right]$ :

$$
\frac{1-\mu}{n}(r-c)+(1-\gamma G(p))^{n-1} \mu(p-c)-\phi=\frac{1-\mu}{n}(r-c)+\frac{\mu}{n}(r-c)(1-\gamma)^{n-1} .
$$

Solving for $G(p)$ yields the distribution of prices posted at the gatekeeper's site:

$$
G^{*}(p)=\frac{1}{\gamma}\left(1-\left(\frac{\frac{\mu}{n}(r-c)(1-\gamma)^{n-1}+\phi}{\mu(p-c)}\right)^{\frac{1}{n-1}}\right) .
$$

Setting $G^{*}(r)=1$ and solving for $\gamma$ yields the probability a firm lists a price at the gatekeeper's site:

$$
\gamma^{*}=1-\left(\frac{\phi}{\mu(r-c)\left(1-\frac{1}{n}\right)}\right)^{\frac{1}{n-1}} .
$$

Also by hypothesis, $G^{*}\left(p_{L}\right)=0$; hence, the lower support of the putative equilibrium satisfies

$$
\frac{1}{\gamma^{*}}\left(1-\left(\frac{\frac{\mu}{n}(r-c)\left(1-\gamma^{*}\right)^{n-1}+\phi}{\mu\left(p_{L}-c\right)}\right)^{\frac{1}{n-1}}\right)=0 .
$$

Substituting for $\gamma^{*}$ and solving yields:

$$
p_{L}=\frac{n}{n-1} \frac{\phi}{\mu}+c
$$

Finally, notice that the assumption that $\frac{n}{n-1} \frac{\phi}{\mu}+c<r$ implies $c<p_{L}<r, \gamma^{*} \in(0,1)$, and $G^{*}(p)$ is a well-defined atomless cdf on $\left[p_{L}, r\right]$.

The expected profits of a firm that adopts the putative equilibrium strategy are:

$$
\begin{aligned}
k^{*} & =\frac{1-\mu}{n}(r-c)+\frac{\mu}{n}(r-c)\left(1-\gamma^{*}\right)^{n-1} \\
& =\frac{1-\mu}{n}(r-c)+\frac{\phi}{n-1} .
\end{aligned}
$$


It remains to show that a firm can do no better than to adopt the putative equilibrium strategy, $\left(G^{*}, \gamma^{*}\right)$. By construction, a firm earns expected profits of $k^{*}$ for any $p \in$ $\left[p_{L}, r\right]$ posted on the gatekeeper's site. Suppose a firm deviates by posting a price $p^{\prime}$ $\notin\left[p_{L}, r\right]$ on the gatekeeper's site. Clearly, it is not profitable for the firm to deviate by pricing above the monopoly price, so suppose $p^{\prime}<p_{L}$. In this case the deviating firm attracts all consumers with access to the gatekeeper's site with probability one, but earns expected profits that are strictly less than $k^{*}$. Hence, a firm that posts its price on the gatekeeper's site can do no better than select its price based on $G^{*}$. Finally, notice that given the putative equilibrium pricing strategies, a firm is exactly indifferent between posting a price on the gatekeeper's site and not listing; hence, a firm can do no better than to adopt a probability $\gamma^{*}$ of posting its price at the gatekeeper's site. We conclude that the putative equilibrium strategies do, in fact, comprise a Nash equilibrium.

\section{Conclusion}

We have shown that when homogenous product firms pay a positive fee to list their prices at a gatekeeper's site and can price discriminate between consumers purchasing through the gatekeeper's site and those who do not, prices listed at the gatekeeper's site are dispersed but lower than at brick-and-mortar establishments. In particular, there exists a symmetric equilibrium where firms post prices at the price comparison site with probability $\gamma^{*}$ and the price posted is drawn from the distribution function $G^{*}$. Since firms post a price of $r$ at their own websites and $G^{*}$ is atomless with support $\left[p_{L}, r\right]$, it follows that prices listed at the price comparison site are lower than those posted at individual firms' websites with probability one.

\section{References}

[1] Michael R. Baye and John Morgan, "Information Gatekeepers on the Internet and the Competitiveness of Homogeneous Product Markets." American Economic Review, Vol. 91, No. 3 (June 2001), pp. 454-474.

[2] Michael R. Baye, John Morgan, and Patrick Scholten, "Price Dispersion in the Small and in the Large: Evidence from an Internet Price Comparison Site." Mimeo, Princeton University, July 2001.

[3] Caillaud, Bernard and Bruno Jullien, "Chicken and Egg: Competing Matchmakers." Mimeo, GREMAQ and IDEI, Tolouse, and CEPR, April 2001. 
[4] Nahm, Jae, "Information Gatekeepers on the Internet and the Competitiveness of Homogeneous Product Markets: Comment." Mimeo, Hong Kong University of Science and Technology, 2001.

[5] Stahl, Dale O., "Strategic Advertising and Pricing in E-Commerce." Advances in Applied Microeconomics, Vol. 9, pp. 69-100, 2000. 